\title{
E-test determination of antifungal susceptibility of Candida species isolated from turkeys
}

\author{
Ireneusz Sokół ${ }^{1}$, Stanisław Tokarzewski², \\ Kamila Bobrek ${ }^{3}$ and Andrzej Gawe ${ }^{3 凶}$ \\ ${ }^{1}$ Private Veterinary Service, SM-ARTVET 51-361 Wrocław \\ ${ }^{2}$ Private Veterinary Service, AviExpert, 20-827 Lublin \\ ${ }^{3}$ Department of Epizootiology and Clinic of Bird and Exotic Animals, Faculty of Veterinary Medicine, \\ Wrocław University of Environmental and Life Sciences, 50-366 Wrocław, Poland \\ andrzej.gawel@upwr.edu.pl
}

Received: May 14, 2020 Accepted: October 26, 2020

\begin{abstract}
Introduction: Candida species are a natural component of the intestinal tract microflora, but in favourable conditions they can cause superficial, mucosal, or even systemic candidiasis. Poultry production might be a source of human drug-resistant yeast infections, including Candida spp. The limited data concerning the antifungal susceptibility of poultry Candida isolates prompted us to carry out research to determine the susceptibility of isolates from turkey intestinal tracts. Method and Materials: The beak cavity, crop and cloaca were swabbed of 580 turkeys from 58 flocks in western Poland. The susceptibility tests were conducted using the E-test method with amphotericin B, fluconazole, itraconazole, and voriconazole on 52 isolates of C. albicans, C. catenulata, C. glabrata, C. palmioleophila, C. rugosa, C. krusei and C. lusitaniae. Results: All isolates were susceptible to voriconazole. According to the MIC values obtained for amphotericin B and fluconazole, all Candida spp. isolates were classified as susceptible according to the described breakpoints except for C. krusei, which was the only isolate that was amphotericin B-, fluconazole- and itraconazole-resistant. The susceptibility to itraconazole varied: 11 of the Candida isolates were susceptible (21.1\%), 29 were dosedependently susceptible (55.8\%), and 12 isolates were resistant (23.1\%). Conclusion: There are few resistant strains of Candida in turkeys, and the drug resistance varies. When Candida passes from turkeys to humans, there is a wide range of antifungal treatment options.
\end{abstract}

Keywords: antimicrobials, Candida, E-test, MIC, susceptibility, turkeys.

\section{Introduction}

Fungi are a natural component of the intestinal tract microflora and have great influence on gut health. Both filamentous fungi and yeasts were isolated from the poultry gastrointestinal tract with Candida species predominating, followed by Trichosporon spp., Geotrichum spp., Rhodotorula spp., and Saccharomyces spp. (18, 22, 23, 25). The best-known yeast species is Candida albicans, an opportunistic fungal pathogen responsible for superficial and mucosal or systemic infections. Other species such as C. parapsilosis, C. rugosa, C. famata, C. tropicalis, and C. krusei might also cause candidiasis in poultry $(13,19,20)$. Lesions may be observed all along the length of the intestinal tract, but mostly occurs in the beak and crop, where during severe infections pseudomembrane or diphtheric membrane formations are observed, sometimes with "cheese-like" material (7). Our previous research has shown that antimicrobial treatment of turkeys, especially with beta-lactams, predisposes them to fungal infestations of the gastrointestinal tract (23). The highest number of species isolated in that research belonged to the Candida genus, which is a potentially pathogenic group. Birds can be a reservoir of harmful fungi to humans, and direct transmission of dermatophytes from poultry to workers was confirmed (27). Avian faeces as a potential source of yeast exposure for bird owners and poultry house workers are often discussed $(2,25)$. Due to the increasing number of drug-resistant Candida isolates in humans $(17,26)$, and a lack of research into the antifungal susceptibility of Candida species isolated from turkeys' intestinal tracts, we decided to address the lack of data. The aim of this study was to determine amphotericin B, fluconazole, 
itraconazole and voriconazole susceptibility of Candida using the E-test method on isolates from turkeys' intestinal tracts. The E-test method was chosen because previous comparative analyses of susceptibility testing methods showed that it is a reliable alternative to the broth microdilution method $(3,11,16)$. Moreover, this method is easier and less time-consuming thanks to its design as a plastic strip impregnated with a predefined concentration gradient of an antifungal drug.

\section{Material and Methods}

The isolates of fungi were obtained from British United Turkeys Big 6, from 58 commercial flocks in western Poland managed by one company in the years 2014-2017, as described previously $(22,23)$. The birds were monitored during the rearing period for gastrointestinal disorders, and there was no case of clinical mycosis of the gastrointestinal tract. Ten birds from each flock were sampled. The swabs taken from beak cavity, crop and cloaca were cultured on Sabouraud glucose agar with chloramphenicol (Emapol, Poland) and incubated at $37^{\circ} \mathrm{C}$ for 48 hours. The strains were isolated and identified using classical mycological diagnostic methods: microbiological cultures and microscopic examination. Identification of the genera of the fungi was based on the morphological characteristics of the isolates and their growth on CHROMagar media (Emapol, Poland). For the susceptibility study, only the cloacal isolates were chosen. For the species identification, a PCR with ITS1 (5'-TCCGTAGGTGAA CCTGCGG-3') and ITS4 (5'-TCCTCCGCTTATTGA TATGC-3') primers (Genomed, Poland) amplified the ITS1-5.8rRNA-ITS2 fragment (29) and the PCR products were sequenced. The genetic material was isolated using the Genomic Mini AX Yeast (A\&A Biotechnology, Poland) according to the manufacturer's instructions. The PCR was performed in a $25 \mu \mathrm{L}$ reaction mixture containing $50 \mathrm{ng}$ of DNA in $2 \mu \mathrm{L}, 0.25 \mu \mathrm{L}$ of each primer at a concentration of $25 \mathrm{mM}, 12.5 \mu \mathrm{L}$ of PCR Mix Plus (A\&A Biotechnology), and $10 \mu \mathrm{L}$ of water. Amplification was carried out in a T100 PCR thermal cycler (Bio-Rad, USA). The PCR was run through initial denaturation at $95^{\circ} \mathrm{C}$ for $5 \mathrm{~min}, 35$ cycles of $95^{\circ} \mathrm{C}$ for $1 \mathrm{~min}$, annealing at $55^{\circ} \mathrm{C}$ for $1 \mathrm{~min}$, and extension at $72^{\circ} \mathrm{C}$ for $2 \mathrm{~min}$, and final elongation at $72^{\circ} \mathrm{C}$ for $10 \mathrm{~min}$. The PCR products were subjected to electrophoresis in a 1.5\% agarose gel stained with SYBR Green (Sigma Aldrich, USA) and visualised under ultraviolet light. They (a 900 bp product for C. glabrata, one of $550 \mathrm{bp}$ for $C$. albicans and a $400 \mathrm{bp}$ length for the rest of the examined species) were sequenced using the PCR primers detailed above designed by Genomed. Raw readings of respective sequences were edited, analysed, and assembled using Mega 6 software (28) and compared to other sequences in the GenBank database. For the susceptibility tests, 52 isolates originating from cloaca samples were selected which classified to 10 strains of C. albicans, C. catenulata, C. glabrata,
C. palmioleophila, and C. rugosa. Additionally, one cloacal isolate of $C$. krusei and one of C. lusitaniae were examined.

Inoculum suspensions. Yeast inoculum suspensions were prepared as described in the Clinical and Laboratory Standards Institute (CLSI) M27-A3 (5). Briefly, inoculum suspensions of Candida spp. isolates were prepared in $0.9 \%$ saline solution and adjusted to a final concentration of 0.5 according to the McFarland standard with approximately $1-5 \times 10^{6} \mathrm{CFU} / \mathrm{mL}$. This suspension was used directly to inoculate agar plates for the E-test (bioMérieux Polska sp. z o.o., Poland).

Antifungal agents. E-test strips for amphotericin $B$ (AMB) 0.002-32 $\mu \mathrm{g} / \mathrm{mL}$, itraconazole (ICZ) $0.002-32 \mu \mathrm{g} / \mathrm{mL}$, voriconazole (VCZ) $0.002-32 \mu \mathrm{g} / \mathrm{mL}$ and fluconazole (FCZ) 0. 016 - $(256 \mu \mathrm{g} / \mathrm{mL})$ were purchased from bioMérieux Polska sp. z o.o.

E-test. The E-test was performed according to the instructions of the manufacturer. For the antifungal susceptibility testing, RPMI 1640 medium containing $2 \%$ glucose (Emapol, Poland) was used. Each solidified medium was inoculated with a sterile swab dipped into the respective inoculum suspension and then evenly smeared over the surface of the plate. The inoculated agar surface was allowed to dry for 15 minutes before the E-test strip was placed on it. The plates were then incubated at $35^{\circ} \mathrm{C}$ for $48 \mathrm{~h}$. After the plates had been incubated for 24 and 48 hours, MICs were read as the lowest drug concentrations at which the border of the ellipse touched the scale on the strip. The final MIC values were based on the consensus between two readers. Guidelines for the in vitro susceptibility of Candida species to fluconazole (FCZ), itraconazole (ICZ), and voriconazole (VCZ) were adapted from the M27-A3 and M60-ED 1 documents from the CLSI $(5,6)$, and the interpretative criteria for amphotericin $\mathrm{B}$ (AMB), which were not defined in CLSI documents, were adopted from the literature $(14,24)$. The lowest concentrations at which $50 \%\left(\mathrm{MIC}_{50}\right)$ and $90 \%\left(\mathrm{MIC}_{90}\right)$ of the isolates were inhibited were determined for each group.

\section{Results}

The MIC ranges and values of $\mathrm{MIC}_{50}$ and $\mathrm{MIC}_{90}$ obtained for amphotericin B, fluconazole, itraconazole, and voriconazole in susceptibility testing determined by the CLSI method are summarized in Table 1.

According to the MIC values obtained for amphotericin B, fluconazole and voriconazole, C. albicans, C. catenulata, C. glabrata, C. palmioleophila, C rugosa, and $C$. lusitaniae isolates were classified as susceptible according to the described breakpoints. C. krusei was the only isolate which was amphotericin B and itraconazole resistant. The MIC values for itraconazole were 0.125 to $8 \mu \mathrm{g} / \mathrm{mL}$, indicating that 11 of the Candida isolates were susceptible $(21.1 \%), 29$ were dose-dependently susceptible $(55.8 \%)$, and 12 isolates were resistant (23.1\%) (Table 2). 
Table 1. MICs $(\mu \mathrm{g} / \mathrm{mL})$ of antifungal agents for Candida isolates determined by E-test

\begin{tabular}{|c|c|c|c|c|c|c|}
\hline $\begin{array}{l}\text { Candida species } \\
\text { (number of strains) }\end{array}$ & Antifungal agent & $\begin{array}{l}\text { MICs } \mu \mathrm{g} / \mathrm{mL} \\
\text { determined by } \\
\text { E-test }\end{array}$ & $\mathrm{MIC}_{50}$ & $\mathrm{MIC}_{90}$ & $\begin{array}{l}\text { Susceptibility } \\
\text { breakpoints }\end{array}$ & $\begin{array}{l}\text { Resistance } \\
\text { breakpoints }\end{array}$ \\
\hline \multirow{4}{*}{ C. albicans (10) } & Amphotericin B & $0.125-1$ & 0.38 & 1 & $\leq 1$ & $>1$ \\
\hline & Fluconazole & $0.125-0.75$ & 0.19 & 0.75 & $\leq 2$ & $\geq 8$ \\
\hline & Itraconazole & $0.125-1$ & 0.38 & 1 & $\leq 0.125$ & $\geq 1$ \\
\hline & Voriconazole & $0.002-0.094$ & 0.012 & 0.094 & $\leq 0.12$ & $\geq 1$ \\
\hline \multirow{4}{*}{ C. catenulata (10) } & Amphotericin B & $0.094-1$ & 0.5 & 1 & $\leq 1$ & $>1$ \\
\hline & Fluconazole & $0.064-16$ & 0.5 & 16 & $\leq 8$ & $\geq 64$ \\
\hline & Itraconazole & $0.032-3$ & 0.075 & 3 & $\leq 0.125$ & $\geq 1$ \\
\hline & Voriconazole & $0.004-0.19$ & 0.094 & 0,19 & $\leq 1$ & $\geq 4$ \\
\hline \multirow{4}{*}{ C. glabrata $(10)$} & Amphotericin B & $0.125-1$ & 0.19 & 1 & $\leq 1$ & $>1$ \\
\hline & Fluconazole & $0.75-4$ & 2 & 4 & $\leq 8$ & $\geq 64$ \\
\hline & Itraconazole & $0.125-0.38$ & 0.125 & 0.38 & $\leq 0.125$ & $\geq 1$ \\
\hline & Voriconazole & $0.012-0.38$ & 0.064 & 0.38 & $\leq 1$ & $\geq 4$ \\
\hline \multirow{4}{*}{ C. palmioleophila (10) } & Amphotericin B & $0.125-0.75$ & 0.19 & 0.75 & $\leq 1$ & $>1$ \\
\hline & Fluconazole & $0.5-2$ & 1 & 2 & $\leq 8$ & $\geq 64$ \\
\hline & Itraconazole & $0.125-8$ & 0.5 & 8 & $\leq 0.125$ & $\geq 1$ \\
\hline & Voriconazole & $0.023-0.125$ & 0.064 & 0,125 & $\leq 1$ & $\geq 4$ \\
\hline \multirow{4}{*}{ C. rugosa (10) } & Amphotericin B & $0.19-0.5$ & 0.25 & 0,5 & $\leq 1$ & $>1$ \\
\hline & Fluconazole & $0.25-1$ & 0.75 & 1 & $\leq 8$ & $\geq 64$ \\
\hline & Itraconazole & $0.125-1$ & 0.38 & 1 & $\leq 0.125$ & $\geq 1$ \\
\hline & Voriconazole & $0.006-0.047$ & 0.012 & 0.047 & $\leq 1$ & $\geq 4$ \\
\hline \multirow{4}{*}{ C. krusei } & Amphotericin B & 1.5 & - & - & $\leq 1$ & $>1$ \\
\hline & Fluconazole & 24 & - & - & $\leq 8$ & $\geq 64$ \\
\hline & Itraconazole & 1 & - & - & $\leq 0.125$ & $\geq 1$ \\
\hline & Voriconazole & 0.38 & - & - & $\leq 0.5$ & $\geq 2$ \\
\hline \multirow{4}{*}{ C. lusitaniae } & Amphotericin B & 0.5 & - & - & $\leq 1$ & $>1$ \\
\hline & Fluconazole & 0.25 & - & - & $\leq 8$ & $\geq 64$ \\
\hline & Itraconazole & 0.19 & - & - & $\leq 0.125$ & $\geq 1$ \\
\hline & Voriconazole & 0.02 & - & - & $\leq 1$ & $\geq 4$ \\
\hline
\end{tabular}

Fluconazole, itraconazole and voriconazole range values according to Clinical and Laboratory Standards Institute (CLSI) literature guidelines for amphotericin B were adapted from references $(11,23)$. Ranges: FCZ $(0.016-256 \mu \mathrm{g} / \mathrm{mL}), \mathrm{ICZ}(0.002-32 \mu \mathrm{g} / \mathrm{mL}), \mathrm{VCZ}(0.002-32 \mu \mathrm{g} / \mathrm{mL})$, and AMB $(0.002-32 \mu \mathrm{g} / \mathrm{mL})$

Table 2. Susceptibility patterns of Candida species isolated from turkeys' intestinal tracts based on MIC values

\begin{tabular}{|c|c|c|c|c|}
\hline $\begin{array}{l}\text { Candida species } \\
\text { (number of strains) }\end{array}$ & Antifungal agent & Susceptible & $\begin{array}{l}\text { Dose-dependently } \\
\text { susceptible }\end{array}$ & Resistant \\
\hline \multirow{4}{*}{ C. albicans (10) } & Amphotericin B & $10(100 \%)$ & - & - \\
\hline & Fluconazole & $10(100 \%)$ & - & - \\
\hline & Itraconazole & $1(10 \%)$ & $7(70 \%)$ & $2(20 \%)$ \\
\hline & Voriconazole & $10(100 \%)$ & - & - \\
\hline \multirow{4}{*}{ C. catenulata $(10)$} & Amphotericin B & $10(100 \%)$ & - & - \\
\hline & Fluconazole & $10(100 \%)$ & - & - \\
\hline & Itraconazole & $1(10 \%)$ & $7(70 \%)$ & $2(20 \%)$ \\
\hline & Voriconazole & $10(100 \%)$ & - & - \\
\hline \multirow{4}{*}{ C. glabrata (10) } & Amphotericin B & $10(100 \%)$ & - & - \\
\hline & Fluconazole & $10(100 \%)$ & - & - \\
\hline & Itraconazole & $5(50 \%)$ & $5(50 \%)$ & - \\
\hline & Voriconazole & $10(100 \%)$ & - & - \\
\hline \multirow{4}{*}{ C. palmioleophila (10) } & Amphotericin B & $10(100 \%)$ & - & - \\
\hline & Fluconazole & $10(100 \%)$ & - & - \\
\hline & Itraconazole & $2(20 \%)$ & $4(40 \%)$ & $4(40 \%)$ \\
\hline & Voriconazole & $10(100 \%)$ & - & - \\
\hline \multirow{4}{*}{ C. rugosa (10) } & Amphotericin B & $10(100 \%)$ & - & - \\
\hline & Fluconazole & $10(100 \%)$ & - & - \\
\hline & Itraconazole & $2(20 \%)$ & $5(50 \%)$ & $3(30 \%)$ \\
\hline & Voriconazole & $10(100 \%)$ & - & - \\
\hline \multirow{4}{*}{ C. lusitaniae (1) } & Amphotericin B & - & $1(100 \%)$ & - \\
\hline & Fluconazole & $1(100 \%)$ & - & - \\
\hline & Itraconazole & - & $1(100 \%)$ & - \\
\hline & Voriconazole & $1(100 \%)$ & - & - \\
\hline \multirow{4}{*}{ C. krusei (1) } & Amphotericin B & - & - & $1(100 \%)$ \\
\hline & Fluconazole & - & $1(100 \%)$ & - \\
\hline & Itraconazole & - & - & $1(100 \%)$ \\
\hline & Voriconazole & $1(100 \%)$ & - & - \\
\hline
\end{tabular}

Values are presented as number of isolates (\%) 


\section{Discussion}

Infections of the intestinal tract, caused by Candida species, are common in birds. Usually, candidiasis in poultry does not present in its severe form, and many cases might not be diagnosed. The outbreaks reported in the literature are mostly related to a combination of alterations in the host's immune system defences, such as the integrity of the mucocutaneous barrier, an imbalance in the normal microflora, failure of proper immune response or an immunocompromised condition through stress, and the virulence factors of the Candida strain $(13,21)$. In poultry production, healthy intestinal tracts in reared birds are crucial to realising the expected profit, and consequently, Candida infections should be documented and widely analysed. The only analysis of antifungal susceptibility of Candida spp. in poultry isolates was conducted by Subramanya et al. (25) in chicken flocks. In previous research on yeast occurrence in turkey intestinal tracts, Candida was the most frequently isolated genus $(22,23)$. Among Candida species, C. albicans, C. rugosa, C. catenulata, C. glabrata, C. palmioleophila, and C. krusei were isolated in the present study, which were previously noted as constituents of avian microbiota $(4,8,10,12,13,25)$. The results of antifungal susceptibility of Candida species isolated from turkeys' intestinal tracts showed that all isolates were susceptible to voriconazole $(\leq 1 \mu \mathrm{g} / \mathrm{mL})$, whereas in contrasting findings the chicken Candida isolates susceptibility interval was $0.06-8 \mu \mathrm{g} / \mathrm{mL}$ and C. albicans, C. tropicalis, and C. krusei were among the resistant strains (25). In our research the Candida spp. susceptibility to amphotericin B and fluconazole was high, and among 52 Candida isolates, only one, the C. krusei strain, was amphotericin B resistant. The susceptibility to amphotericin B of chicken Candida isolates varied, and the chicken C. krusei strains were susceptible to amphotericin B, and resistant to fluconazole (25). Comparison of our results to Subramanya et al. (25) data shows the need for further research on antifungal susceptibility of Candida spp. in poultry because of the variability of susceptibility among the Candida species isolated from turkeys and chickens. The lack of data is not the only reason why the investigation should be conducted. Birds and their faeces are a source of many fungi which can threaten human health $(2,30)$. The frequency of isolation of Candida in poultry confinements (in litter and settled dust) was approximately $50 \%$ (15), which can be dangerous for poultry house workers, especially those with immunosuppressive diseases. The knowledge deficiency about the antimicrobial susceptibility of poultry Candida species might engender a human health risk, and the antifungal resistance of these microorganisms should be monitored, due to the risk of zoonotic infections. The common form of invasive candidiasis in humans is candidaemia, a blood stream infection which often results in long-term hospitalisation and death (1). For years, the most common species isolated from blood was C. albicans (8), but the latest data show an increasing proportion of non-C. albicans infections caused by Candida species which were also isolated from poultry (24). Falagas et al. (8) noted that $21 \%$ of Candida isolates obtained from patients' blood were resistant to one or more antifungal agents. Among turkey isolates, $23 \%$ of the strains were resistant to one antifungal, and multi-drug resistance was observed in one isolate. Candida species isolated from humans are mostly resistant to fluconazole and voriconazole $(8,9)$. In contrast to human isolates, turkey isolates are resistant to itraconazole. The obtained data shows that there are few resistant strains of Candida in turkeys, and the drug resistance varies. In the case of transmission of Candida from turkeys to humans, there is a wide range of antifungal treatment options.

Conflict of Interests Statement: The authors declare that there is no conflict of interests regarding the publication of this article.

Financial Disclosure Statement: The article was financed from the Department of Epizootiology and Clinic of Birds and Exotic Animals statutory sources.

Animal Rights Statement: None required.

\section{References}

1. Aldardeer N., Albar H., Al-Attas M., Edali A., Qutub M., Hassanien A., Alraddadi B.: Antifungal resistance in patients with Candidaemia: a retrospective cohort study. BMC Infect Dis 2020, 20, 55, doi: 10.1186/s12879-019-4710-z.

2. Brilhante R.S., Castelo-Branco D.S., Soares G.D., Astete-Medrano D.J., Monteiro A.J., Cordeiro R.A., Sidrim J.J., Rocha M.F.: Characterization of the gastrointestinal yeast microbiota of cockatiels (Nymphicus hollandicus): a potential hazard to human health. J Med Microbiol 2010, 59, 718-723.

3. Buchta V., Vejsova M., Vale-Silva L.A.: Comparison of disk diffusion test and Etest for voriconazole and fluconazole susceptibility testing. Folia Microbiol (Praha) 2008, 53, 153-160.

4. Cafarchia C., Camarda A., Ramito D., Campula M., Quaglia N.C., Tulio D., Otranto D.: Occurrence of yeasts in cloacae of migratory birds. Mycopathologia 2006, 161, 229-234.

5. Clinical and Laboratory Standards Institute: M27-A3 Reference Method for Broth Dilution Antifungal Susceptibility Testing of Yeasts; Approved Standard - Third Edition. CLSI, Wayne, 2008.

6. Clinical and Laboratory Standards Institute: M60-ED 1: 2017 Performance Standards for Antifungal Susceptibility Testing of Yeasts. CLSI, Wayne, 2017.

7. Dhama, K., Chakraborty S., Verma A., Tiwari R., Barathidasan R., Kumar A., Singh S.: Fungal/mycotic diseases of poultrydiagnosis, treatment and control: a review. Pak J Biol Sci 2013, 16, 1626-1640.

8. Falagas M., Roussos N., Vardakas K.: Relative frequency of albicans and the various non-albicans Candida spp. among candidemia isolates from inpatients in various parts of the world: a systemic review. Int $\mathrm{J}$ Infect Dis 2010, 14, e954-966, doi: 10.1016/j.ijid.2010.04.006.

9. Juayang A., Lim J., de los Reyes Z., Tuante M., Batiles Z., Guino-o J., Villanueva F., de los Reyes G.: Antifungal resistance of Candida species in Bacolod City, Philippines. J Infect Dis Epidemiol 2019, 5, 76, doi, 10.23937/2474-3658/1510076. 
10. Kemoi E.K., Okemo P., Bii C.C.: Isolation of Candida species in domestic chicken (Gallus gallus) droppings in Kabigeriet village, Nakuru country Kenya. Eur Sci J 2013, 9, 309-318, doi: 10.19044/esj.2013.v9n36p\%25p.

11. Kumar D., Bhattacharyya S., Gupta P., Banerjee G., Singh M.: Comparative Analysis of Disc Diffusion and E-test with Broth Micro-dilution for Susceptibility Testing of Clinical Candida Isolates Against Amphotericin B, Fluconazole, Voriconazole and Caspofungin. J Clin Diagn Res 2015, 9, DC01-DC04, doi: 10.7860/JCDR/2015/14119.6735.

12. Lin M.Y., Huang K.J., Kleven S.H.: In vitro comparison of the activity of various antifungal drugs against new yeast isolates causing thrush in poultry. Avian Dis 1989, 33, 416-421.

13. Moretti A., Piergili Fioretti M., Bonicio L., Pasquali P., Delrossi E.: Isolation of Candida rugosa from Turkeys. J Vet Med B 2000, 47, 433-439.

14. Negri M., Henriques M., Svidzinski T.I., Paula C.R., Oliveira R.: Correlation between Etest, disk diffusion, and microdilution methods for antifungal susceptibility testing of Candida species from infection and colonization. J Clin Lab Anal 2009, 23, 324-330.

15. Okiki P., Ogbimi A.: Micro-fungi and mycotoxins in poultry dust. Estud Biol 2011, 33, 81-86, doi: 10.7213/reb.v32i76/81.22870.

16. Ranque S., Lachaud L., Gari-Toussaint M., Michel-Nguyen A., Mallié M., Gaudart J., Bertout S.: Interlaboratory reproducibility of Etest amphotericin B and caspofungin yeast susceptibility testing and comparison with the CLSI method. J Clin Microbiol 2012, 50, 2305-2309.

17. Redding S., Smith J., Farinacci G., Rinaldi M., Fothergill A., Rhine-Chalberg J., Pfaller M.: Resistance of Candida albicans to Fluconazole During Treatment of Oropharyngeal Candidiasis in a Patient with AIDS: Documentation by In Vitro Susceptibility Testing and DNA Subtype Analysis. Clin Infect Dis 1994, 18, 240-242, doi: 10.1093/clinids/18.2.240.

18. Shokri H., Khosravi A., Nikaein D.: A comparative study of digestive tract mycoflora of broilers with layers. Int J Vet Res $2011,5,1-4$.

19. Singh S., Fatima Z., Hameed S.: Predisposing factors endorsing Candida infections. Infez Med 2015, 23, 211-223.

20. Sokół I., Bobrek K., Tokarzewski S., Gaweł A.: Candidiasis in poultry. Med Weter 2015, 71, 731-735.
21. Sokół I., Gaweł A., Bobrek K.: Investigation of the correlation between virulence factors and genotypic profiles of Candida albicans isolated from turkeys. Pol J Vet Sci 2018, 21, 29-33, doi: $10.24425 / 119018$.

22. Sokół, I., Gaweł A., Bobrek K.: The Prevalence of Yeast and Characteristics of the Isolates from the Digestive Tract of Clinically Healthy Turkeys. Avian Dis 2018, 62, 286-290, doi: 10.1637/11780-121117-Reg.1.

23. Sokół I., Tokarzewski S., Bobrek K., Gaweł A.: The effect of the administration of different antimicrobial formulations on the fungal infestation of the gastrointestinal tract in turkeys. Pak Vet J 2017, 37, 475-479.

24. Song Y.B., Suh M.K., Ha G.Y., Kim H.: Antifungal Susceptibility Testing with Etest for Candida Species Isolated from Patients with Oral Candidiasis. Ann Dermatol 2015, 27, 715-720.

25. Subramanya S.H., Sharan N.K., Baral B.P., Hamal D., Nayak N., Prakash P.Y., Sathian B., Bairy I., Gokhale S.: Diversity, in-vitro virulence traits and antifungal susceptibility pattern of gastrointestinal yeast flora of healthy poultry, Gallus gallus domesticus. BMC Microbiol 2017, 17, 113, doi: 10.1186/s12866017-1024-4.

26. Swoboda-Kopec E., Wroblewska M., Rokosz A., Krawczyk E., Luczac M., Sulik-Tyszka B.: Susceptibility of clinical isolates of Candida glabrata to new triazoles. Int J Antimicrob Ag 2003, 21, 360-361.

27. Quandt S., Schultz M., Feldman S., Vallejos Q., Marin A., Carrillo L., Arcury T.: Dermatological illness of immigrant poultry processing workers in North Carolina. Arch Environ Occup Health 2005, 60, 165-169, doi: 10.3200/AEOH.60.3.165-169.

28. Tamura K., Stecher G., Peterson D., Filipski A., Kumar S.: MEGA6: Molecular Evolutionary Genetics Analysis version 6.0. Mol Biol Evol 2013, 30, 2725-2729.

29. White T.J., Bruns T.D., Lee S.B., Taylor J.W.: Amplification and direct sequencing of fungal ribosomal RNA genes for phylogenetics, In: PCR protocols: a guide to methods and applications, edited by M.A. Innis, D.H. Gelfand, J.J. Sninsky, T.J. White, Academic Press, Inc., New York, 1990, pp. 315-322.

30. Ziółkowska G., Tokarzewski S.: Occurrence of moulds in reproductive goose flocks in southern-eastern Poland. Bull Vet Inst Pulawy 2007, 51, 553-556. 